\title{
Perancangan Sistem Keamanan Ruangan Akibat Kebocoran Gas Berbasis Internet of Things (IoT)
}

\author{
Indra maidoni ${ }^{1}$, Elfizon ${ }^{2}$ \\ 1.2 Universitas Negeri Padang \\ Jl. Prof. Dr. Hamka air tawar, Padang, Indonesia \\ indramaidony@gmail.com ${ }^{1}$,elfizon@ft.unp.ac.id ${ }^{2}$
}

\begin{abstract}
Abtrak-The role of LPG gas at this time is very important for human life both in households and in industry. However, gas can have a negative impact, especially if it is not known that a leak has occurred from the LPG cylinder or storage area. For this reason, this final project aims to design a room security system due to gas leaks based on internet of things (IoT). where using the MQ-6 sensor and the MQ-2 sensor to detect gas or smoke then the system will automatically sterilize the room from the gas entering the room, the system is also equipped with a hydrant in case of fire and notifications connected to the network using the ESP8266 module which will send right data or notification to the whattsap application if there is a gas leak to the owner of a room that is not in place so that the room owner knows that a gas leak has occurred.
\end{abstract}

Key words-arduino nano, MQ-6 sensor, MQ-2 sensor, 12 VDC water pump, ESP8266 module, Icd, 12 VDC dc fan

Abstrak-Peranan gas LPG pada saat ini sangatlah penting bagi kehidupan manusia baik di rumah tangga maupun di industri. Namun, gas dapat berdampak negatif, terutama bila tidak diketahui telah terjadi kebocoran dari tabung atau tempat penyimpanan gas LPG (liquefied Petroleum Gas) tersebut. Untuk itu tugas akhir ini bertujuan untuk membuat perancangan sistem keamaanan ruangan akibat kebocoran gas berbasis internet of things (IoT), dimana menggunakan sensor MQ-6 dan sensor MQ-2 untuk mendeksi gas ataupun asap kemudian secara otomatis sistem akan mensterilkan ruangan dari gas yang masuk keruangan tersebut, sistem juga dilengkapi dengan hidran apabila terjadi kebakaran dan notifikasi yang terhubung dengan jaringan menggunakan modul ESP8266 yang akan mengirim kan data atau notifikasi ke aplikasi whattsap apabila terjadi kebocoran gas ke pemilik ruangan yang tidak ada ditempat sehingga pemilik ruangan tau telah terjadi kebocoran gas.

Kata kunci-arduino nano, sensor MQ-6, sensor MQ-2, pompa air 12 VDC, modul ESP8266, Icd, kipas dc 12 VDC

\section{PENDAHULUAN}

Peranan gas LPG pada saat ini sangatlah penting bagi kehidupan manusia baik di rumah tangga maupun di industri. Namun, gas dapat berdampak negatif, terutama bila tidak diketahui telah terjadi kebocoran dari tabung atau tempat penyimpanan gas LPG tersebut. Penyebab dari bocor tabung gas ini bisa terjadi karena kebocoran pada selang, tabung atau pada regulatornya yang tidak terpasang dengan baik dan tabung gas yang didistribusikan memang kualitasnya kurang baik atau rusak fisik.

Keamanan adalah salah satu aspek penting dalam sebuah sistem ataupun lingkungan, baik lingkungan perumahan, perkantoran, kampus, tempat wisata pedesaan ataupun perkotaan, pusat perbelanjaan ataupun tempat-tempat lain terutama tempat-tempat yang rawan terjadi kebakaran. Kebakaran seringkali terjadi akibat kelalaian manusia yang disebabkan karena beberapa faktor seperti kebocoran tabung gas LPG (Liquid Petroleum Gas) berukuran kecil ataupun besar, akibat puntung rokok yang dibuang sembarangan, hubungan pendek arus listrik yang menimbulkan api dan merambat kebagian lainya. Kebakaran tentunya merugikan banyak pihak baik moril maupun materil, dan tidak sedikit juga menimbulkan kematian.
Kita dapat mengurangi terjadinya kebakaran tersebut, salah satunya dengan merancang sistem keamanan ruangan akibat kebocran gas dan pemberian hydrant yang berfungsi untuk memadamkan api apabila terjadi kebakaran akibat kebocoran gas LPG karena sangat banyak digunakan oleh masyarakat untuk kebutuhan sehari-hari mengolah makanan dan minuman. LPG saat ini bukan merupakan barang mewah yang hanya dimiliki oleh kalangan atas tetapi sampai pelosok desa pun saat ini telah beralih menggunakan gas LPG. Tidak jarang kita menemukan tabung gas yang bocor akhirnya meledak karena kurang paham dalam penggunaannya.

Alat yang akan dirancang adalah sebuah alat yang efisien dan terjangkau untuk mencegah sebuah kerugian yang diakibatkan oleh kebakaran dengan cara membuat sistem keamanan ruangan akibat kebocoran gas LPG. Sistem pendeteksi adalah sebuah sistem keamanan terintegrasi secara otomatis. Memberikan informasi keadaan dari suatu peristiwa atau kondisi yang dapat diaplikasikan pada perumahan, perkantoran, kampus atau instansi yang membutuhkan.

Salah satu solusi dari penelitian ini adalah pemilik rumah atau bangunan dapat mengetahui bahwa telah terjadi kebocoran dirumah atau di ruangan mereka dan dapat mengambil mengirim perintah pencegahan untuk mebuka jendela diruangan tersebut secara 
otomatis agar gas yang memenuhi ruangan tersebut dapat keluar dari ruangan tersebut,dan menyiramkan air apa bila sensor mendeteksi asap yg tandanya telah terjadi kebakaran jadi kemungkinan terburuk dari kebocoran gas tersebut bisa diminimalisir sampai penghuni rumah datang .

\section{METODE}

Metode yang digunakan untuk penelitian ini adalah membuat perancangan sistem kebocoran gas dalam ruangan berbasis Internt of things (Iot)

\section{A. Blok Diagram}

Tujuan dari perancangan ini adalah untuk mempermudah dalam pembuatan alat. Bagian hardware meliputi rangkaian power supply 12 V, Modul ESP8266, Modul Mikrokontroler Arduino Nano, Sensor asap dan gas MQ2 dan MQ6, Fan DC, Servo, Relay, dan Pompa DC. Sedangkan bagian software berkaitan dengan Arduino IDE dan PHP yaitu bahasa C yang akan di download-kan ke mikrokontroler dan $W E B$.

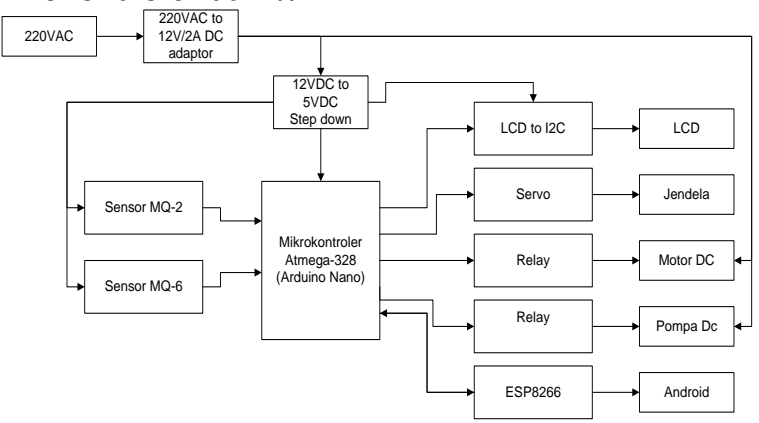

Gambar 1 : Blok Diagram

\section{Prinsip Kerja Alat}

Alat ini akan bekerja secara otomatis dalam mendeteksi kebocoran gas ataupun asap ketika terjadi kebakaran di rumah. Sensor mq2 dan mq6 secara realtime mendeteksi gas dan asap disekitarnya. Data-data sensor ini kemudian diolah di mikrokontroller untuk di analisa apakah besarnya gas yang terdeteksi masih dibawah ambang batas (threshold) atau tidak. Ketika sensor mq2 dan mq6 mendeteksi adanya gas, maka secara otomatis servo akan membuka pintu jendela, kontak relay akan terhubung untuk mengaktifkan fan dc. Dengan demikian gas yang terdeteksi akan dibuang oleh fan DC melalui jendela yang telah dibuka oleh servo. Bersamaan dengan hal ini ESP8266 akan mengirimkan informasi tersebut ke smartphone pengguna melalui aplikasi mesanger yaitu WhatsApp. Dengan demikian pengguna bisa mengetahui potensi kebakaran yang akan terjadi dirumahnya, walaupun dari tempat yang berjauhan.

Ketika sensor MQ2 mendeteksi adanya asap, maka secara otomatis kontak relay akan terhubung untuk mengaktifkan pompa DC untuk memompa air dari dalam tabung untuk disiramkan ke sumber api agar sumber api bisa dipadanmkan. Bersamaan dengan hal ini ESP8266 akan mengirimkan informasi tersebut ke smartphone pengguna melalui aplikasi mesanger yaitu WhatsApp. Dengan demikian pengguna bisa mengetahui potensi kebakaran yang akan terjadi dirumahnya, walaupun dari tempat yang berjauhan.

Disamping itu pada smartphone pengguna akan dibuatkan aplikasi yang akan menghubungkan antara smartphone pengguna dengan alat ini agar bisa dikontrol dan dimonitoring dari jarak jauh seperti membuka dan menutup pintu jendela ataupun dalam hal memantau nilai-nilai sensor gas dan asap dari jarak jauh.

\section{B. Flowchart Program}

Prinsip kerja dari alat ini dijelaskan melalui suatu gambar atau bagan yang menunjukkan langkah atau urutan suatu program

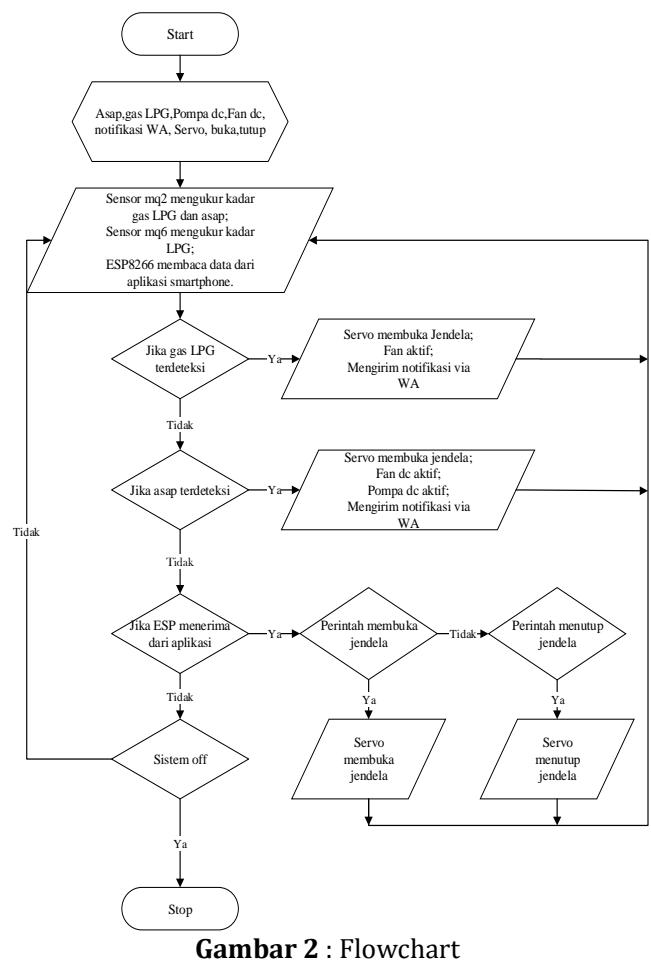

\section{Perancangan Hardware}

Perancangan mekanik merupakan suatu proses atau tahapan dalam pembuatan tugas akhir ini. Perancangan ini bertujuan mengurangi kesalahan serta agar memudahkan dalam membuat alat sehingga mendapatkan hasil yang maksimal 


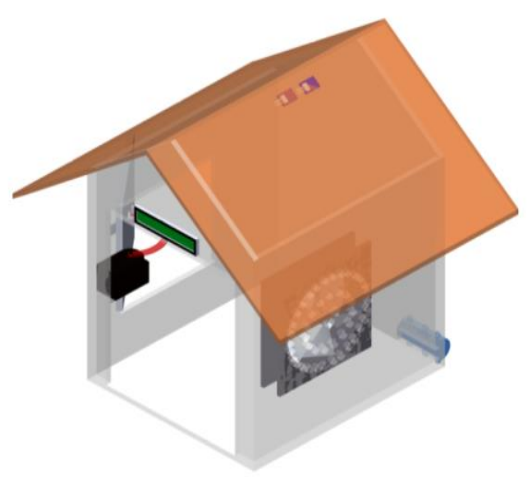

Gambar 3 : Perancangan mekanik

Aplikasi smartphone dibuat dengan menggunakan aplikasi App Inventor dihalaman web ai2.appinventor.mit.edu. Berikut adalah desain aplikasi smartphone yang akan digunakan untuk mengontrol alat ini.

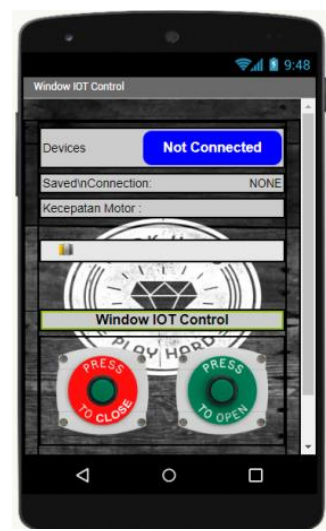

Gambar 4 : Desain Aplikasi Smartphone

\section{HASIL DAN PEMBAHASAN}

Perangkat mekanik sangat berpengaruh terhadap keberhasilan dibuatnya inkubator. Perangkat mekanik yang sesuai akan mendukung hardware dan software sehingga sistem sesuai dengan yang diharapkan. Pada penelitian ini, yang dimaksud dengan perangkat mekanik yaitu adalah perangkat prototype ruangan. Adapun bentuk prototype ditunjukkan pada Gambar 21.

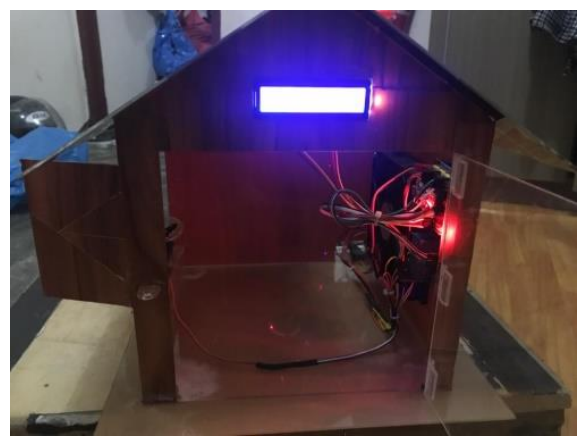

Gambar 5 : Prototype dari depan

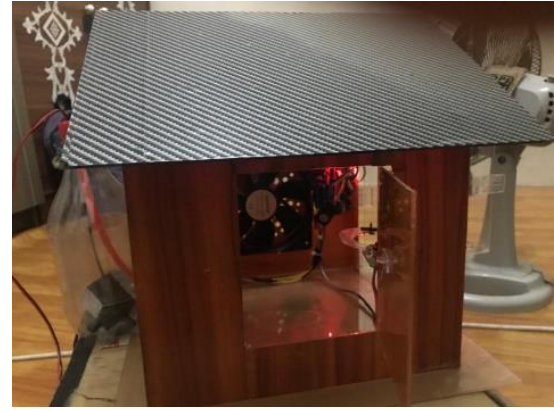

Gambar 6 : prototype dari samping

\section{Hasil Pengujian Hardware}

Pengujian sensor MQ-6

Ledakan Gas pada kandungan 1.8\% - 10\% termasuk kategori sempurna sehingga sangat dahsyat daya hancurnya berlangsung secara berantai, kekuatannya tergantung dari jumlah campuran yang meledak. Pada saat meledak seluruh oksigen yang ada didaerah itu akan terpakai habis dan menjadi hampa udara, sehingga jika ada orang didaerah sekitarnya disamping mendapat luka bakar juga akan kesulitan bernafas. Bangunan sekitarnya akan porak poranda dilanda oleh udara yang bolak balik. Gas yang meledak pada kandungan 1.8\% s/d 10\% ini hakekatnya tidak diikuti oleh kebakaran.

Tabel 1 standar dan pembagi PPM

\begin{tabular}{|l|l|l|l|}
\hline \multicolumn{1}{|c|}{ PPM } & \multicolumn{1}{|c|}{ PEMBAGI } & \multicolumn{1}{c|}{ HASIL } & $\begin{array}{l}\text { PROSENTA } \\
\text { SE (\%) }\end{array}$ \\
\hline 1 & $1 / 1.000 .000$ & $\begin{array}{l}0.00000 \\
1\end{array}$ & 0.0001 \\
\hline 10 & $10 / 1.000 .000$ & 0.00001 & 0.001 \\
\hline 100 & $100 / 1.000 .000$ & 0.0001 & 0.01 \\
\hline 1000 & $1.000 / 1.000 .000$ & 0.001 & 0.1 \\
\hline 10.000 & $10.000 / 1.000 .000$ & 0.01 & 1.0 \\
\hline 100.000 & $\begin{array}{l}100.000 / 1.000 .00 \\
0\end{array}$ & 0.1 & 10 \\
\hline $\begin{array}{l}1.000 .00 \\
0\end{array}$ & $\begin{array}{l}1.000 .000 / 1.000 .0 \\
00\end{array}$ & 1 & 100 \\
\hline
\end{tabular}

Tabel 2 pengujian MQ-6

\begin{tabular}{|c|c|c|}
\hline $\begin{array}{c}\text { PPM } \\
\text { STANDART }\end{array}$ & PPM UJI & $\begin{array}{c}\text { WAKTU } \\
\text { MENSTERILKAN } \\
\text { PROTOTIPE }\end{array}$ \\
\hline $18.000 / 1.8 \%$ & $22.000 / 2.2 \%$ & $10-30$ detik \\
\hline $18.000 / 1.8 \%$ & $21.000 / 2.1 \%$ & $10-30$ detik \\
\hline $18.000 / 1.8 \%$ & $19.000 / 1.9 \%$ & $10-30$ detik \\
\hline
\end{tabular}

Dari table pengujian diatas dapat dliat hasil dari pengujian sensor MQ-6, dimana alat diseting dengan PPM standar yaitu 18.000 ppm yang sama dengan $1.8 \%$. lalu prototype disemprotkan gas untuk menguji sensor bekerja atau tidak, lalu didapat hasil pengujian pertama dengan hasil 22.000/2.2\% ppm, pengujian kedua $21.000 / 2.1 \%$ ppm dan pengujian ketiga 19.000/1.9\% 
ppm dimana pada pengujian tersebut gas yang terdeteksi melebihi ppm staandar yang artinya secara otomatis sistem aktif untuk mensterilkan prototype dari gas tersebut. Waktu yang diperlukan oleh sistem untuk mensterilkan rata-rata adalah sekitar 10-30 detik .

Dan pada gambar grafik dibawah dapat kita liat bagimana sistem sedanga diuji dengan menyemprot gas secara bertahap kedalam prototyte.

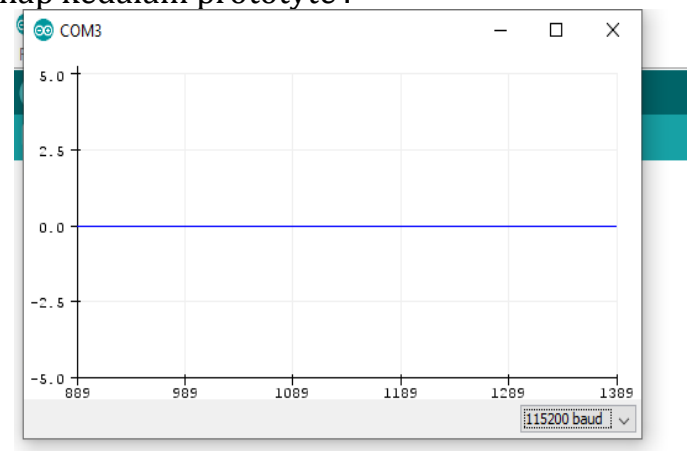

Gambar 7 : Grafik sebelum pengujian MQ-6

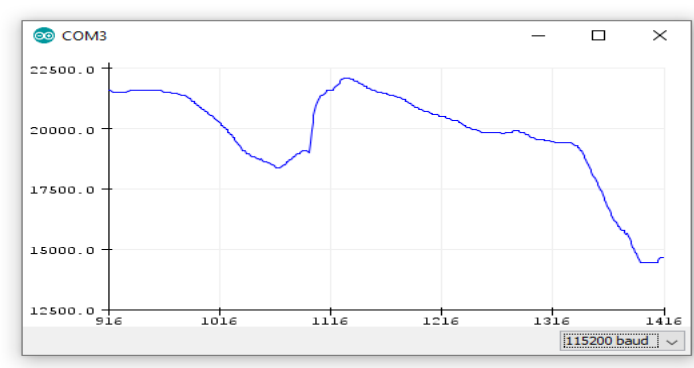

Gambar 8 : Grafik saat pengujian MQ-6

a. Pengujian sensor MQ-2

Pengujian sensor MQ-2 dilakukan dengan cara membakar selembar tisu untuk mengasilkan asap dan melihat respone sensor terhadap asap, dimana disini MQ-2 berfungsi untuk mendeteksi asap maka dari itu MQ-2 diprogram untuk mendeteksi PPM lebih rendah dimana PPM stamdar nya adalah sebesar $4000 / 0.4 \%$ PPM yang berarti apabila sensor mendeteksi $0,4 \%$ maka sistem akan berjalan. semua sistem pada alat akan berjalan dimana jendela, kipas DC dan pompa akan hidup secara bersamaan untuk mengeluarkan asap dan mematikan api yang menimbulkan asap.

Tabel 3 pengujian MQ-2

\begin{tabular}{|c|c|c|}
\hline $\begin{array}{c}\text { PPM } \\
\text { STANDART }\end{array}$ & PPM UJI & $\begin{array}{c}\text { WAKTU } \\
\text { MENSTERILKAN } \\
\text { PROTOTIPE }\end{array}$ \\
\hline $4.000 / 0.4 \%$ & $5.000 / 0.5 \%$ & 5 -20 detik \\
\hline $4.000 / 0.4 \%$ & $4.000 / 0.4 \%$ & 5 -20 detik \\
\hline $4.000 / 0.4 \%$ & $6.000 / 0.6 \%$ & 5 -20 detik \\
\hline
\end{tabular}

\section{b. Pengujian modul ESP8266}

Modul ESP8266 pada alat berfungsi sebagai modul Wi-Fi dan pengolahan data input dari sensor sehingga menghasilkan output yang diinginkan. Pada modul ESP8266 ini pemograman yang dibuat menggunakan software Arduino IDE. Sama halnya dengan menggunakan mikrokontroler Arduino, modul ESP8266 ini juga memerlukan library manager sendiri agar bisa digunakan atau diprogram.Pengukuran pada modul ESP8266 ini bertujuan untuk mengetahui berapa tegangan sumber daya untuk modul ESP8266, sumber daya modul ESP8266 5 Volt DC sedangkan saat pengukuran menggunakan multimeter mendapatkan hasil tegangan sebesar 4,9 Volt. dari pengukuran yang telah dilakukan hasil pengukuran sudah mendekati dengan sumber tegangan modul ESP8266. Pengujian selanjutnya yaitu pengujian konektivitas internet bertujuan untuk memastikan bahwa modul ESP8266 bekerja dengan baik. Pengujian yang pertama dilakukan adalah memeriksa apakah modul ESP8266 dapat terkoneksi dengan jaringan Wi-Fi atau access point yang menyediakan jaringan internet. Pengujian ini dilakukan dengan cara menghubungkan ESP8266 dengan power supply $5 \mathrm{~V}$ dan menunggu sampai terhubung dengan access point atau Wi-Fi yang telah disetting pada program sebelumnya. Untuk melihat terhubungnya modul ESP8266 dengan jaringan internet dapat dilihat pada tampilan LCD

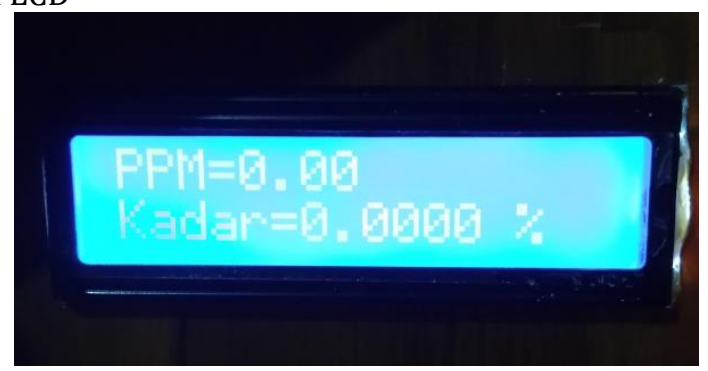

Gambar 9 : Gambar lcd terhubung jaringan

Hasil Pengujian Software

Tabel 4 waktu tempuh data kepada aplikasi android

\begin{tabular}{|c|c|c|}
\hline Waktu uji alat & $\begin{array}{c}\text { Waktu pada } \\
\text { aplikasi }\end{array}$ & Selisih waktu \\
\hline 00.41 .00 & 00.41 .22 & 22 detik \\
\hline 01.00 .00 & 01.10 .23 & 23 detik \\
\hline 02.05 .00 & 02.05 .15 & 15 detik \\
\hline 02.18 .00 & 02.18 .21 & 21 detik \\
\hline 02.45 .00 & 02.45 .20 & 20 detik \\
\hline 07.38 .00 & 07.38 .21 & 21 detik \\
\hline 10.50 .00 & 10.50 .14 & 14 detik \\
\hline 12.15 .00 & 12.15 .27 & 27 detik \\
\hline 12.40 .00 & 12.40 .24 & 24 detik \\
\hline 12.55 .00 & 12.55 .12 & 12 detik \\
\hline \multicolumn{2}{|c|}{ Rata-rata selisih waktu } & 19.9 detik \\
\hline
\end{tabular}


Hasil pengujian waktu tempuh pengiriman whatsapp melalui chat-api dijelaskan dalam tabel sebagai berikut:

Tabel 3.5 hasil pengujian pengiriman Whatsapp melalui Chat-Api

\begin{tabular}{|c|c|c|c|c|}
\hline ID & Nama & No. WA & Status & Waktu \\
\hline 24 & $\begin{array}{c}\text { Marta } \\
\text { Zuriadi }\end{array}$ & 6281372267162 & Terkirim & $\begin{array}{c}5 \\
\text { Sekon }\end{array}$ \\
\hline 26 & $\begin{array}{c}\text { Indra } \\
\text { maidoni }\end{array}$ & 6282169073657 & Terkirim & $\begin{array}{c}3 \\
\text { Sekon }\end{array}$ \\
\hline 29 & $\begin{array}{c}\text { Aulia } \\
\text { Novira }\end{array}$ & 6282386607513 & Terkirim & $\begin{array}{c}8 \\
\text { Sekon }\end{array}$ \\
\hline 31 & Afis resa & 6289637380232 & Terkirim & $\begin{array}{c}6 \\
\text { Sekon }\end{array}$ \\
\hline 32 & $\begin{array}{c}\text { Wahyu } \\
\text { darmawan }\end{array}$ & 6285374713378 & Terkirim & $\begin{array}{c}7 \\
\text { Sekon }\end{array}$ \\
\hline 33 & $\begin{array}{c}\text { Keke } \\
\text { wahyuni }\end{array}$ & 6282180880307 & Terkirim & $\begin{array}{c}5 \\
\text { Sekon }\end{array}$ \\
\hline \multicolumn{4}{|c|}{ Rata-rata } & $\begin{array}{c}5,67 \\
\text { Sekon }\end{array}$ \\
\hline
\end{tabular}

Berdasarkan table di atas aplikasi notifikasi messenger dimana pengujian dilakukan dengan menggunakan beberapa nomor dengan bergantian untuk mengetahui seberapa efektif pengiriman notifikasi melalui aplikasi whatsapp dan untuk mengetahui berapa lama rata-rata waktu sistem mengirim notifikasi ke aplikasi Whatsapp .

\section{PENUTUP}

Berdasarkan hasil pengujian dan analisa hardware dan software pada Perancangan Sistem Keamanan Ruangan Akibat Kebocoran Gas Berbasis internet of things (IoT) maka dapat disimpulkan bahwa perancangan Sistem Keamanan Ruangan Akibat Kebocoran Gas Berbasis internet of things (IoT) dirancang menggunakan sensor gas MQ-2 dan MQ-6 sebagai pendeteksi gas yang bocor memenuhi ruangan tersebut dan dapat dilihat dari monitoring melalui LCD dan aplikasi smartphone. Sistem keamanan ruangan ini diuji dengan menyemprotkan gas kedalam prototype dan membakar tisu sehingga sensor dapat mendeteksi gas dan asap sehingga jendela terbuka , fan dan pompa hidup apa bila kedua sensor atau salah satu mendeteksi gas atau asap. Respon dari alat ini untuk mengirimkan data ke android saat terjadinya kebocoran tidak terlalu lama setelah terjadimya kebocoran sehingga pemilik ruangan dapat segera mengetahui telah terjadinya kebocoran gas diruangan tersebut. Kelebihan alat ini dari alat yang sebelunnya adalah notifikasi yang diberikan melalui whattshap yang dimana aplikasi ini adalah aplikasi yang bnya digunakan sekarang dan kelebihan yang lain dari alat ini adalah bisa mengontrol secara manual untuk mengaktifkan sistem walaupun tidak terjadi kebocoran diruangan tersebut.

\section{DAFTAR PUSTAKA}

[1] Unknown, "Mengenal Arduino Nano Cyber-Code Media," 2016. [Online]. Available: http://familycybercode.blogspot.com/2016/01/mengenalarduino-nano.html. [Accessed: 30-Dec-2019].

[2] F. S. Agung, M. Farhan, Rachmansyah, and E. P. Widiyanto, "Sistem Deteksi Asap Rokok Pada Ruangan Bebas Asap Rokok Dengan Keluaran Suara," AMIK GI MDP, 2016.

[3] Baskara, "MQ 6 Sensor LPG, ISO-Butane, Propane," 2013.

[4] M. Servo, "Pengendali Motor Servo Berbasis Mikrokontroler Basic Stamp 2sx Untuk Mengembangkan Sistem Robotika," pp. 47-54.

[5] A. Andrizal and D. Yendri, "Pengendali Pompa Pengisi Galon Air Berbasis Sensor Waterflow Dan Mini PC," J. RESTI (Rekayasa Sist. dan Teknol. Informasi), vol. 1, no. 2, p. 106, 2017.

[6] R. L. Kahimpong, M. Umboh, and B. Maluegha, “Otomatis Berbasis Arduino Uno Atmega328," J. Online Tek. Mesin, vol. 6, pp. 69-81, 2013.

[7] T. Indriyani and M. Ruswiansari, "Kontrol Jarak Jauh Sistem Irigasi Sawah Berbasis Internet of Things ( IoT )," J. Tek. Inform., pp. 41-48, 2017.

[8] D. Nataliana, I. Syamsu, And G. Giantara, "Sistem Monitoring Parkir Mobil menggunakan Sensor Infrared berbasis RASPBERRY PI," J. Elkomika, vol. 2, no. 1, pp. 68-84, 2017.

[9] H. N. Lengkong, A. A. E. Sinsuw, and A. S. M. Lumenta, "Perancangan Penunjuk Rute Pada Kendaraan Pribadi Menggunakan Aplikasi Mobile GIS Berbasis Android Yang Terintegrasi Pada Google Maps," pp. 18-25, 2015.

[10] Herpa, Andre Perioza. Rancang Bangun Sistem Monitoring Kadar Gas dan Kontrol Jendela Untuk Pengendali Kadar Udara dalam Ruangan Berbasis Web. Bandar Lampung: Universitas Lampung. 2019.

\section{Biodata Penulis}

Indra Maidoni, lahir di Pasar Ahad, 7 Mei 1998. Menyelesaikan studi DIV Teknik Elektro Industri pada Jurusan Teknik Elektro Fakultas Teknik Universitas Negeri Padang.

Elfizon, M.Pd.T lahir di Lima Puluh Kota , 25 Agustus 1985. Menyelesaikan studi S1 di Universitas Negeri Padang tahun. Pendidikan S2 di Universitas Negeri Padang tahun. Saat ini terdaftar sebagai dosen pengajar pada jurusan teknik elektro Universitas Negeri Padang. 